\title{
Interpretations and DFT Calculations for Polypropylene/Cupper Oxide Nanosphere
}

\author{
Mohamed. G. El-Desouky 1,*(i), Mohamed. Abd El-Wahab ${ }^{1}{ }^{(\mathbb{C})}$, Ashraf. A. El-Bindary ${ }^{2(\mathbb{D})}$ \\ 1 Egyptian propylene and polypropylene company, Port Said 42511, Egypt; ch.moh.gamal@ gmail.com (M.G.E-D.) \\ mohamed_abdelwahab1983@yahoo.com (M.A.E.-W); \\ 2 Chemistry Department, Faculty of Science, Damietta University, Damietta, Egypt; abindary@ yahoo.com(A.A.E.-B.); \\ * Corresponding author: ch.moh.gamal@gmail.com (M.G.E-D.)
}

Scopus Author ID 57194898913

Received: 8.03.2021; Revised: 5.04.2021; Accepted: 8.04.2021; Published: 26.04.2021

\begin{abstract}
The electronic properties of polymers and polymers reacting with metal oxides can be studied using molecular modeling. Polypropylene (PP) is a synthetic, thermoplastic polymer with high electrical resistivity in this sense. The effect of the addition of metal oxides such as copper oxide $(\mathrm{CuO})$ on the electronic properties of PP was investigated using a computational analysis based on density functional theory. To research PP electronic properties and PP/CuO nanocomposite, DFT theory at B3LYB/6$311 \mathrm{~g}(\mathrm{~d}, \mathrm{p})$ level was chosen. The addition of nanosphere metal oxide increased the reactivity of the studied model structures for nanocomposite, according to the results of total dipole moment (TDM) and HOMO/LUMO bandgap energy calculations. Because of the interaction of metal oxide with the original polymer, the energy bandgap values decreased.
\end{abstract}

Keywords: Polypropylene; CuO; DFT; TDM and HOMO/LUMO bandgap.

(C) 2021 by the authors. This article is an open-access article distributed under the terms and conditions of the Creative Commons Attribution (CC BY) license (https://creativecommons.org/licenses/by/4.0/).

\section{Introduction}

The most common matrix for nanocomposites research may be semi-crystalline polypropylene (PP), a useful and flexible commodity thermoplastic. PP is currently used extensively in the packaging, automotive, and aerospace sectors. The structural stability, high isotacticity, good mechanical performance, narrow molecular weight distribution [1-3], and good optical properties of PP are among the key reasons for its popularity. Incorporating nanoparticles in the PP matrix has sparked intense interest among polymer scientists in recent years due to its promising industrial applications in various fields. Even at low filler material, nanocomposites with strong filler dispersion deliver significant improvements in mechanical, thermal, electrical, optical, and physicochemical properties [4-6].

Copper oxide $(\mathrm{CuO})$ is an effective optoelectronic material with a high excitation binding energy of $153 \mathrm{eV}$ and a wide direct band-gape of $1.7 \mathrm{eV}$ (room temperature) [7-9]. $\mathrm{CuO}$ is used in various industries, including healthcare, rubber, varistors, paint, ceramics, and cosmetics. Furthermore, nanocomposite PP has the potential to be used in environmental applications. Antibacterial $\mathrm{PP} / \mathrm{TiO}_{2}$ nanofibers were created for biomaterial applications. According to flexural, effect, and strength performance, PP/organophilic clay nanocomposites injected had better mechanical properties than PP. Meanwhile, PP/Multiwall carbon nanotubes (MWCNT) have significantly improved the properties [9,10]. Electrical conductivity and electromagnetic interference shielding were also high in PC/PP CNT Nanocomposites. 
Graphene Oxides (GO), which is also used as a PP nanofiller to enhance chemical, thermal, and mechanical behavior, is one of the most important Carbon nanomaterials. Experimental comparison of mechanical and thermal properties of PP, talc/PP, and pp/Clay nanocomposites [11-13]. For several molecular systems, different classes of computational methods and molecular simulation were successfully used to elucidate various molecular properties, including physical, chemical, and thermal properties [14]. The experimental methods, on the other hand, some physical parameters, such as TDM, have been suggested as good measures of molecular reactivity by various researchers. The reactivity of the studied structure increases as the TDM is increased and the bandgap energy is decreased. In terms of the charge on the surface, another descriptor for reactivity and active site of the studied structure is indicated [15]. As previously described, this could be suggested by mapping the molecular electrostatic potential (MESP). By mapping MESP, one can detect the active site on a given surface based on color distribution. Furthermore, Cellulose nano-whiskers were used to improve the properties of PP. As a result, molecular modeling at the DFT: B3LYP/6-311g $(\mathrm{d}, \mathrm{p})$ level is utilized in the present computational work to study PP and PP's electronic properties interacted with $\mathrm{CuO}[16,17]$.

\section{Materials and Methods}

\subsection{Calculation details.}

Molecular models for PP and PP interactions with $\mathrm{CuO}$ were developed, first through $\mathrm{O}$ and then through $\mathrm{Cu}$. At the Spectroscopy Department, we use Gaussian 09 tools. At the B3LYP/6-311g(d,p) stage, the model structures are optimized using DFT theory TDM. and the band difference energy of the highest occupied molecular orbital and the lowest unoccupied molecular orbital (HOMO/LUMO) are measured at the same stage of theory [18].

\section{Results and Disscusion}

\subsection{Building model molecule.}

To calculate the electronic properties of polypropylene and polypropylene/ $\mathrm{CuO}$ composites. The model structures that reflect $\mathrm{PP}$ and the interaction of $\mathrm{PP}$ with $\mathrm{CuO}$ must first be developed. To reflect the PP molecule, models began with four units of PP monomers. Figure 1 depicts the model structure of the PP assumed structure. Since PP and $\mathrm{CuO}$ can interact through a hydrogen bond, several probabilities are used to interact $\mathrm{CuO}$ with the PP molecule.

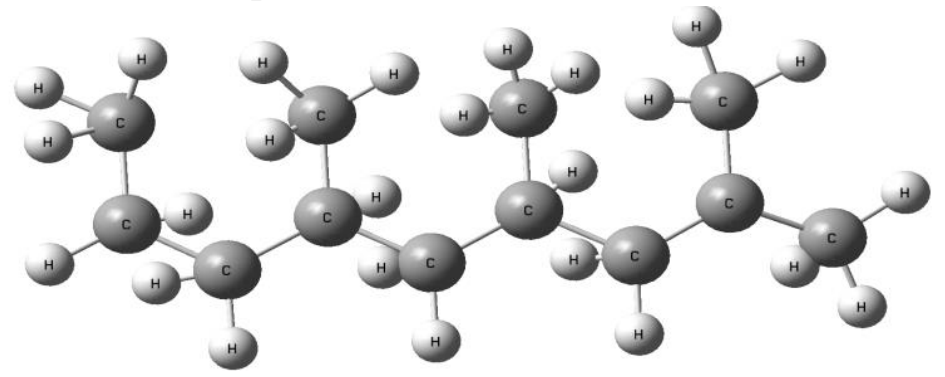

Figure 1. B3LYP/6-311g(d,p) optimized structure of polypropylene model molecule.

The probabilities of interaction between $\mathrm{PP}$ and $\mathrm{CuO}$ nano metal oxide, which will be investigated here, are based on hydrogen atoms, with numbers 12, 14, 16, 17, 20, 33, 37, and 38 reflecting all of the PP polymer's alleged active sides.On the other hand, $\mathrm{CuO}$ 's interaction with PP could occur in one of two ways: through the Copper $(\mathrm{Cu})$ atom or through the oxygen 
(O) atom. To report the analysis of all probabilities, two classes of postulates are simulated $[19,20]$.

\subsection{Total dipole moment TDM and HOMO/LUMO bandgap energy calculations.}

In Figures 2, 3, and 4, the prospects of PP polymer and $\mathrm{PP}$ nanocomposite with $\mathrm{CuO}$ nano metal oxide occurring by hydrogen atoms are shown by numbers $12,14,16,17,20,33$, 37, and 38. TDM and HOMO/LUMO bandgap energy are essential measures of polymeric materials' electronic properties. TDM is a material reactivity measure, and HOMO/LUMO bandgap energy expresses the material's electronic form (conductor, semiconductor, or insulator). For the model structures of $\mathrm{PP}$ polymer and postulate interaction of $\mathrm{CuO}$ nano metal oxide according to the two postulate classes, TDM as Debye and HOMO/LUMO bandgap energy as eV were used [21,22]. Table 1 shows the results of the calculations. Figure 2 shows the PP polymer's optimized structure and HOMO/LUMO bandgap [23,24].
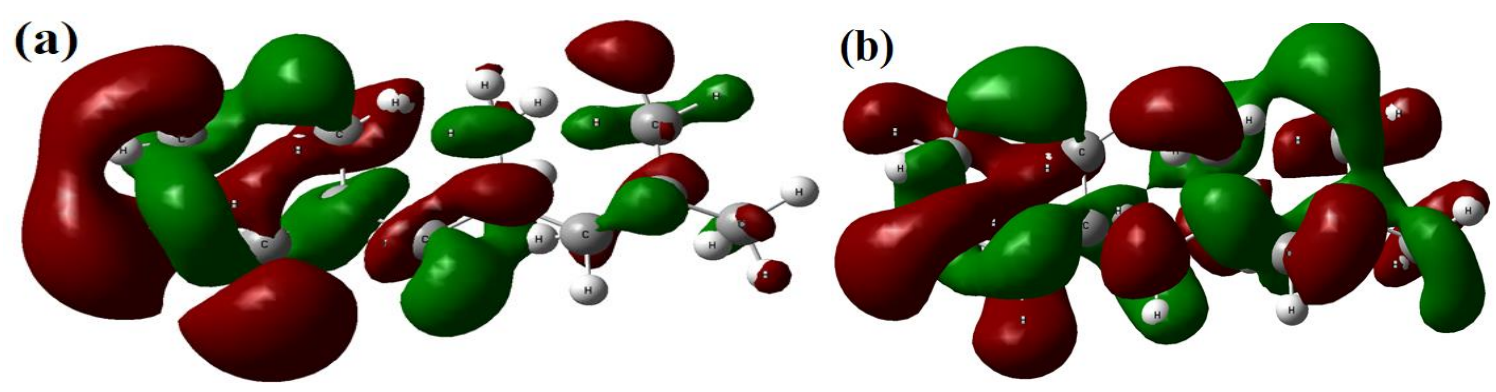

Figure 2. B3LYP/6-311g $(\mathrm{d}, \mathrm{p})$ polypropylene molecule (a) HOMO model; (b) LUMO.

Table 1. Using DFT theory B3LYP/6-311(d, p) level for PP, calculated total dipole moment (TDM) as Debye and $\mathrm{HOMO} / \mathrm{LUMO}$ band gap energy $(\Delta \mathrm{E})$ as $\mathrm{eV}$ and decorated $\mathrm{PP}$ with $\mathrm{CuO}$ once through $\mathrm{Cu}$ atom and once through $\mathrm{O}$ atom for all postulate active sides[25].

\begin{tabular}{|c|c|c|c|}
\hline $\begin{array}{c}\text { Structure } \\
\text { No. }\end{array}$ & Structure & TDM & $\Delta \mathbf{E}$ \\
\hline & $\mathrm{PP}$ & 3.7 & 1.2 \\
\hline 1 & $\mathrm{PP}+\mathrm{CuO} \mathrm{H} 14$ & 11.14 & 0.93 \\
\hline 2 & $\mathrm{PP}+\mathrm{CuO} \mathrm{H} 20$ & 11.28 & 0.74 \\
\hline 3 & $\mathrm{PP}+\mathrm{CuO} \mathrm{H} 12$ & 11.79 & 0.19 \\
\hline 4 & $\mathrm{PP}+\mathrm{CuO}$ H37 & 9.15 & 0.35 \\
\hline 5 & $\mathrm{PP}+\mathrm{CuO} \mathrm{H} 17$ & 20.34 & 0.88 \\
\hline 6 & $\mathrm{PP}+\mathrm{CuO} \mathrm{H} 16$ & 18.94 & 0.40 \\
\hline 7 & $\mathrm{PP}+\mathrm{CuO} \mathrm{H} 38$ & 9.26 & 0.43 \\
\hline 8 & $\mathrm{PP}+\mathrm{CuO} \mathrm{H} 33$ & 13.11 & 0.49 \\
\hline 9 & $\mathrm{PP}+\mathrm{OCu} \mathrm{H} 14$ & 8.28 & 0.98 \\
\hline 10 & $\mathrm{PP}+\mathrm{OCu} \mathrm{H} 20$ & 4.97 & 0.62 \\
\hline 11 & $\mathrm{PP}+\mathrm{OCu} \mathrm{H} 12$ & 13.83 & 0.59 \\
\hline 12 & $\mathrm{PP}+\mathrm{OCu} \mathrm{H} 37$ & 2.615 & 0.69 \\
\hline 13 & $\mathrm{PP}+\mathrm{OCu} \mathrm{H} 17$ & 6.22 & 0.338 \\
\hline 14 & $\mathrm{PP}+\mathrm{OCu} \mathrm{H} 16$ & 15.6 & 0.57 \\
\hline 15 & $\mathrm{PP}+\mathrm{OCu} \mathrm{H} 38$ & 6.08 & 0.56 \\
\hline 16 & $\mathrm{PP}+\mathrm{OCu} \mathrm{H} 33$ & 12.35 & 0.41 \\
\hline
\end{tabular}




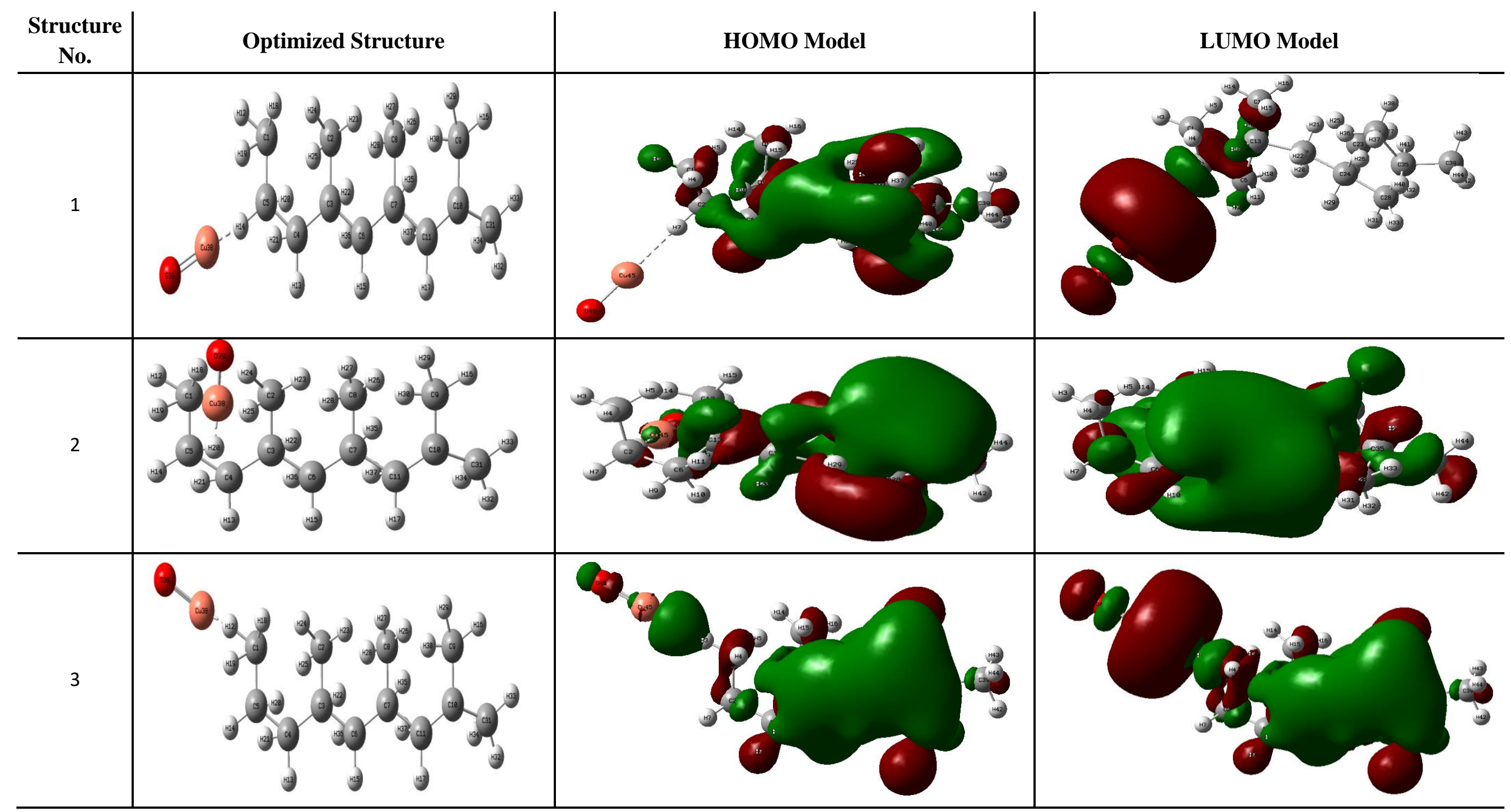




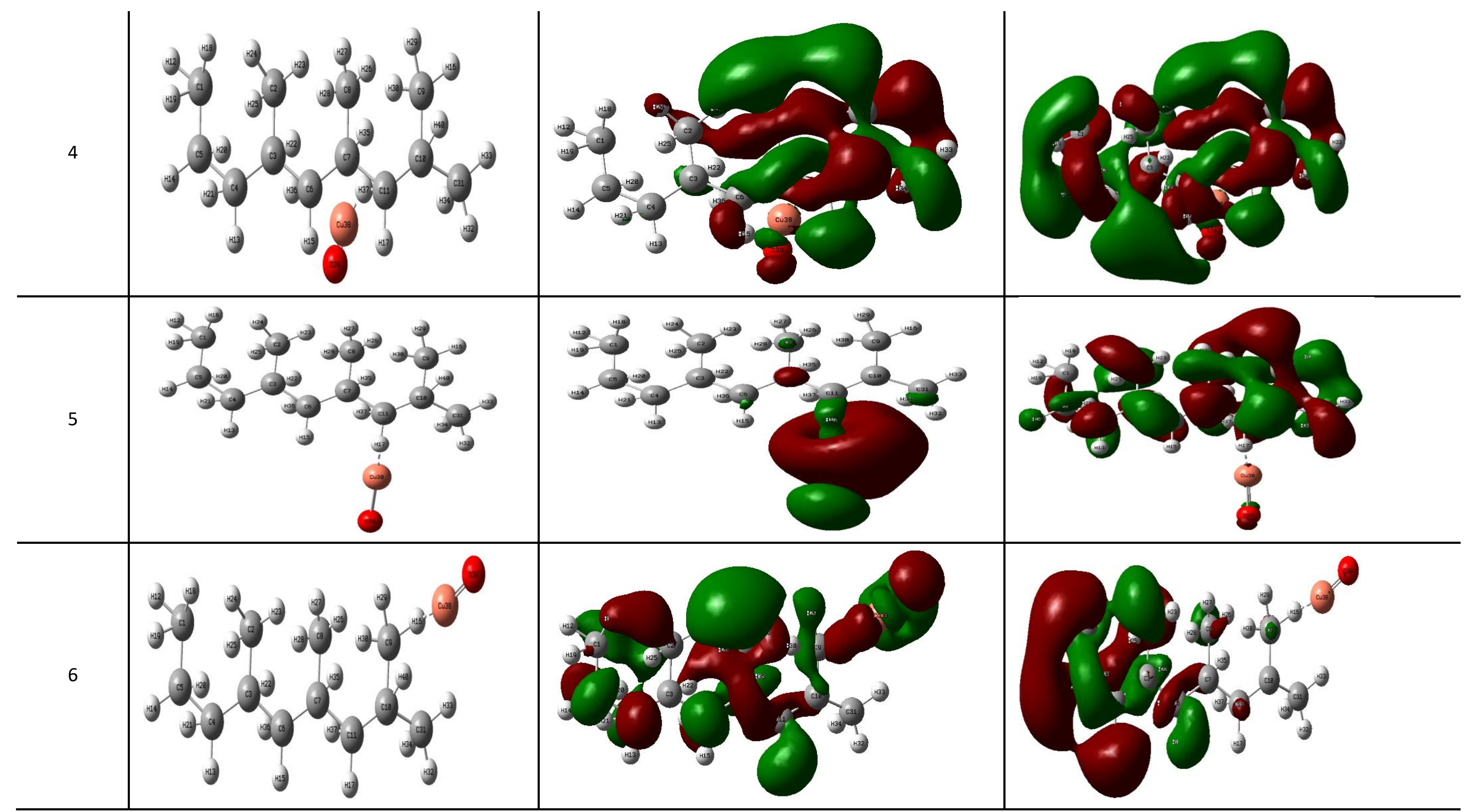




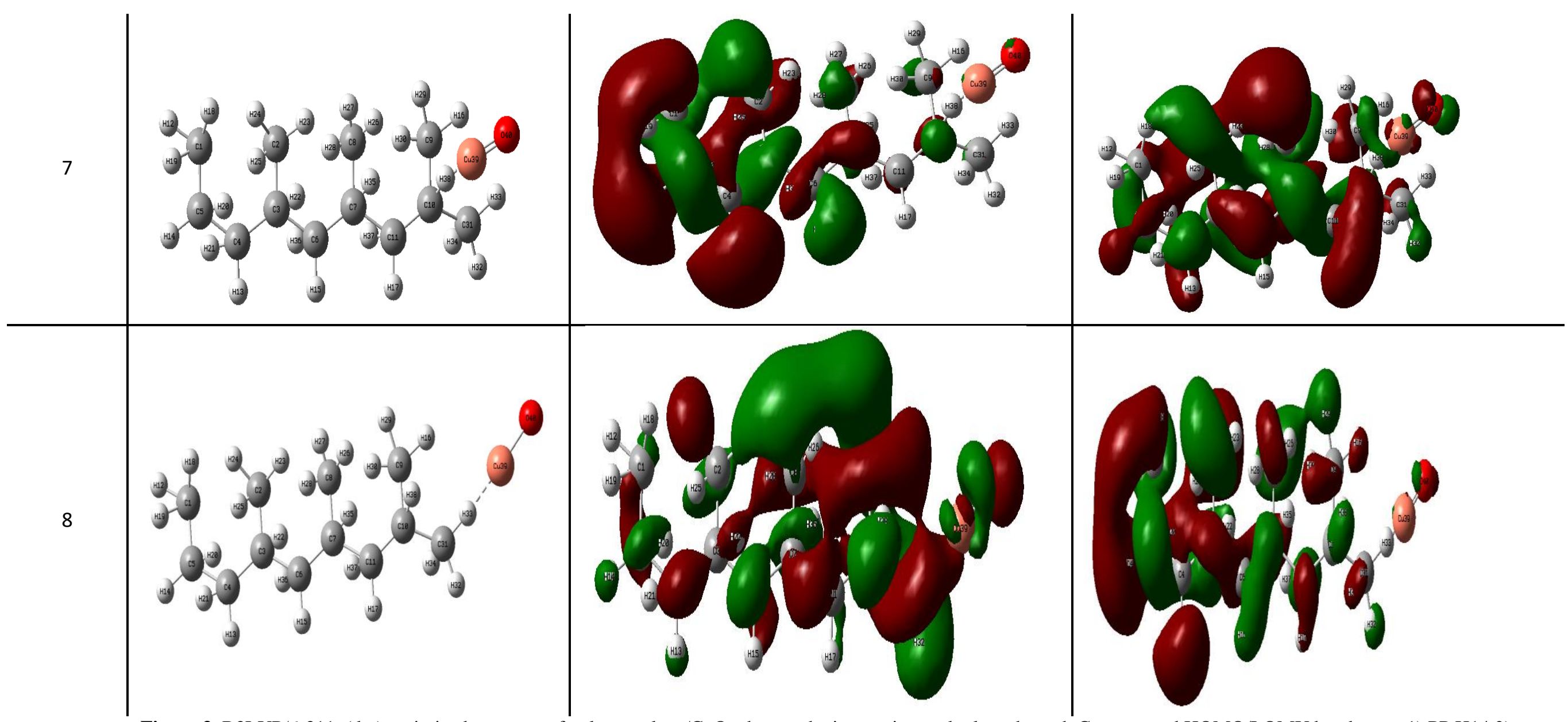

Figure 3. B3LYP/6-311g(d,p) optimized structure of polypropylene/CuO whereas the interaction took place through $\mathrm{Cu}$ atom and HOMO/LOMU bandgap at 1) PP H14 2) PP H20 3) PP H12 4) PP H37 5) PP H17 6) PP H16 7) PP H38 8) PP H33. 


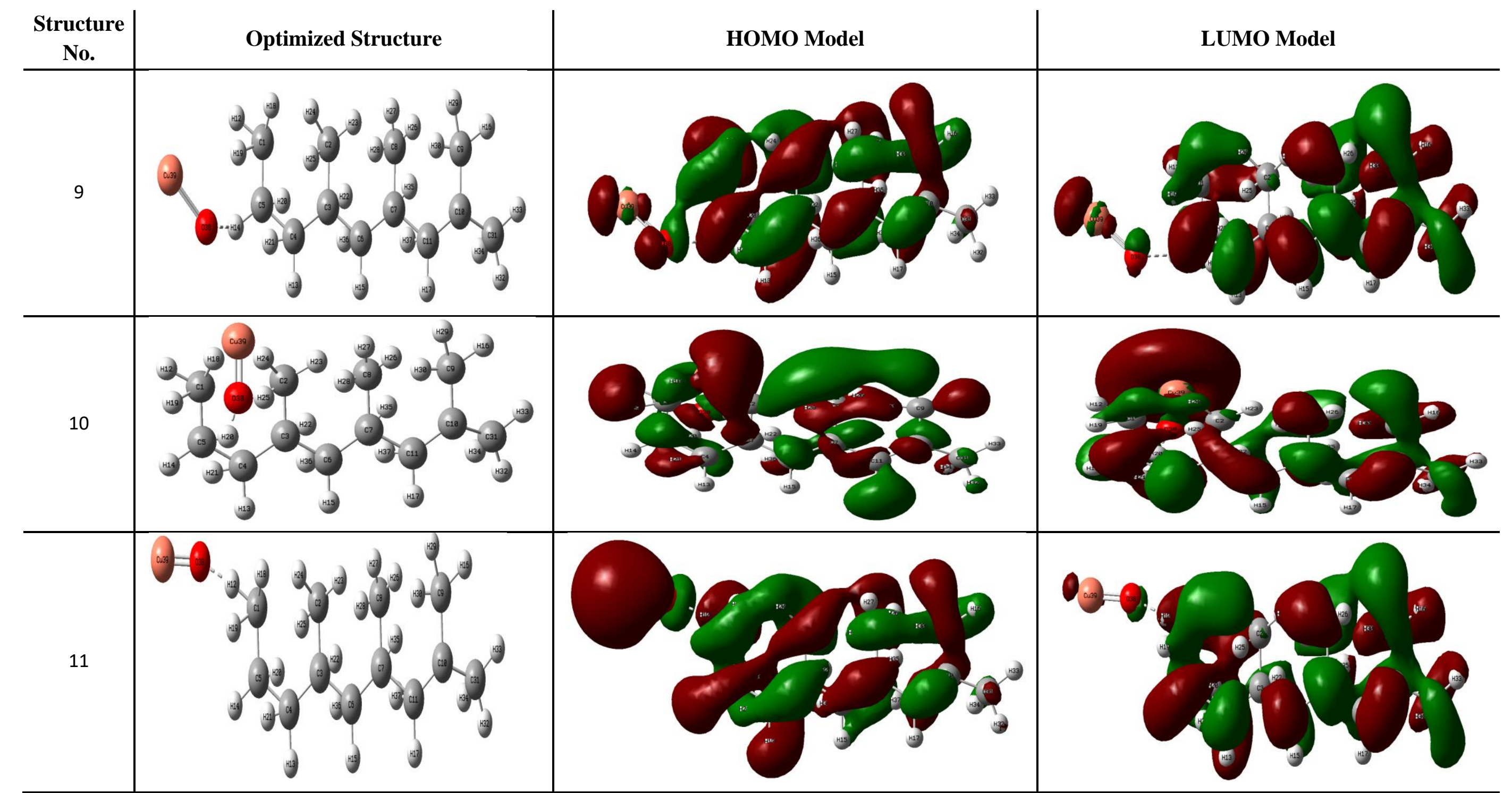




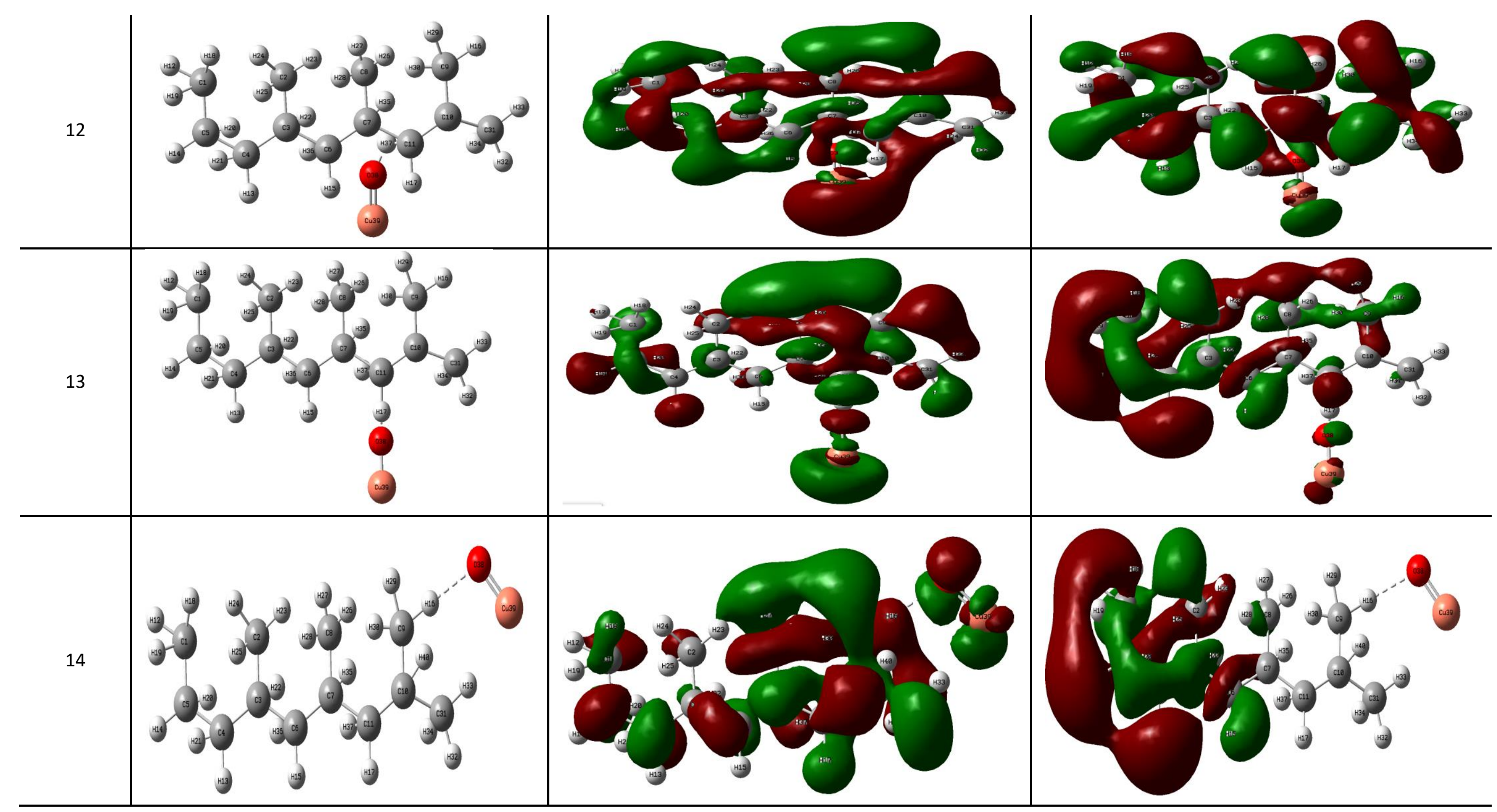




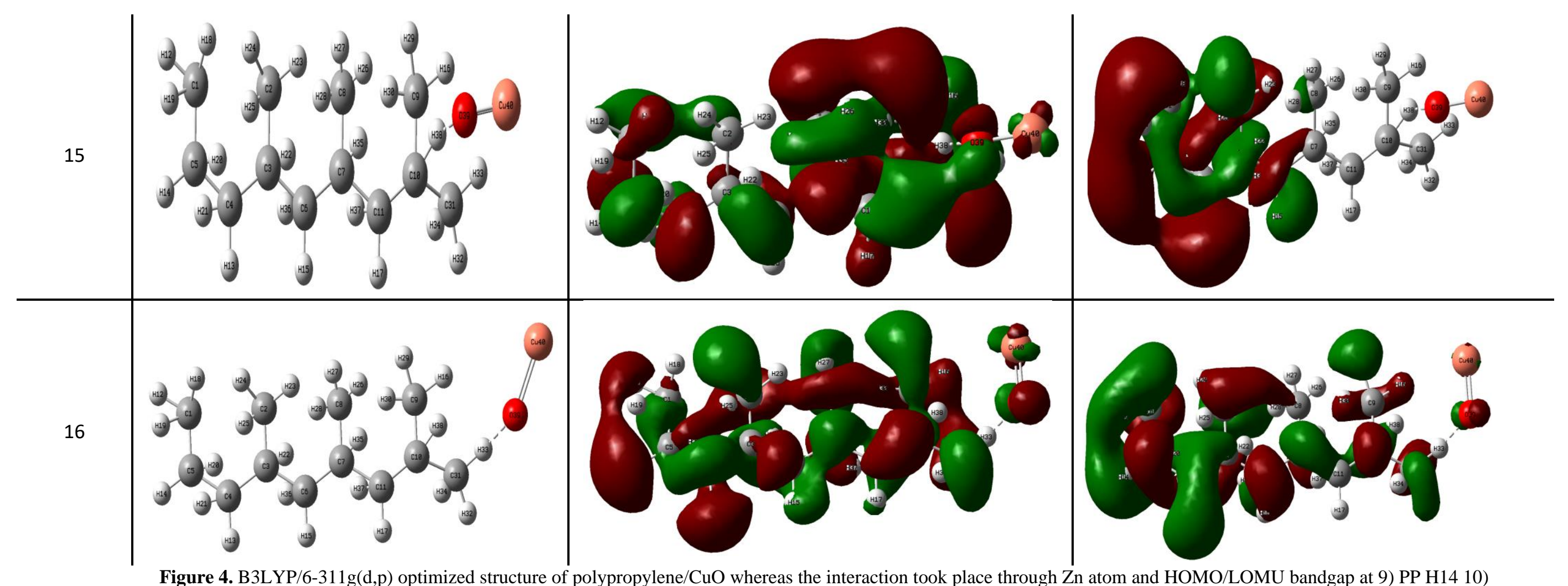

PP H20 11) PP H12 12) PP H37 13) PP H17 14) PP H16 15) PP H38 16) PP H33. 


\subsection{Illustration of possibity of interaction.}

\subsubsection{CuO-PP Interaction.}

For PP polymer, the TDM and bandgap energy $\triangle \mathrm{E}$ values were 3.7 Debye and $1.2 \mathrm{eV}$, respectively. TDM values for various postulate locations of interaction with supposed active sides H14, H20, H12, H37, H17, H16, H38, and H33 were 11.14, 11.28, 11.79, 9.15, 20.34, $18.94,9.26$, and 13.11 Debye mean. whereas the bandgap energy $\Delta \mathrm{E}$ values were $0.93,0.74$, $0.19,0.35,0.88,0.40,0.43$, and 0.49 . TDM was increased for all postulate positions while bandgap energy $\mathrm{E}$ was decreased, indicating that $\mathrm{CuO}$ nano metal oxide could affect all positions[26]. These findings showed that $\mathrm{CuO}$ has a significant impact on the PP molecule reactivity, with TDM of PP-CuO composites being many times higher than TDM of the PP molecule[27,28]. $\mathrm{CuO}$ nano metal oxide decoration has a greater impact on the highest TDM value and the lowest bandgap energy E values. With TDM, the highest reactivity is at hydrogen atom number $17,16,33$, and the lowest reactivity is at $\Delta \mathrm{E}$ Table 1.

These findings support the impact of $\mathrm{CuO}$ on PP's electronic properties, with the $\Delta \mathrm{E}$ value of PP-CuO composites being lower than that of the PP molecule[29]. To put it another way, $\mathrm{PP}-\mathrm{CuO}$ composites evolved into semiconductor materials. The interaction at hydrogen numbers 17 and 14 had the lowest value for $\Delta \mathrm{E}$. These results suggested that PP interaction with $\mathrm{CuO}$ through the $\mathrm{Cu}$ atom could occur with atoms 17,14 .

\subsubsection{OCu-PP Interaction.}

TDM values for different postulate positions of interaction with supposed active sides H14, H20, H12, H37, H17, H16, H38, and H33 were 8.28, 4.97, 13.83, 2.615, 6.22, 15.6, 6.08, and 12.35 for different postulate positions of interaction with supposed active sides H14, H20, $\mathrm{H} 12, \mathrm{H} 37, \mathrm{H} 17, \mathrm{H} 16, \mathrm{H} 38$, and H33. In the meantime, Debye's bandgap energy $\Delta \mathrm{E}$ was valued at $0.62,0.59,0.69,0.34,0.5,0.56$, and 0.41 , respectively. TDM was increased for all postulate positions while bandgap energy $\mathrm{E}$ was decreased, indicating that $\mathrm{CuO}$ nano metal oxide could affect all positions[30,31]. These findings showed that $\mathrm{CuO}$ has a significant impact on the $\mathrm{PP}$ molecule reactivity, with TDM of PP-CuO composites being many times higher than TDM of the PP molecule. The highest value of TDM and lowest bandgap energy $\Delta \mathrm{E}$ values are more affected by $\mathrm{OCu}$ nano metal oxide decoration. The highest reactivity is at hydrogen atom number 12, 17, 33 with TDM, and lowest $\Delta \mathrm{E}$. From the calculations, HOMO/LUMO bandgap energy $\Delta \mathrm{E}$ of PP molecule equals $1.2 \mathrm{ev}$ Table 1 . The lowest value for $\Delta \mathrm{E}$ was the interaction at hydrogen number 17 and 33[32].

As shown in Figure 5, the TDM and HOMO/LUMO band gap energy $(\Delta \mathrm{E})$ of PP decorated with $\mathrm{CuO}$ by $\mathrm{Cu}$ atoms or $\mathrm{O}$ atoms allowed a major change 13.30 Debye and 0.37 $\mathrm{eV}$, respectively, while for $\mathrm{OCu} 3.78$ Debye and $0.57 \mathrm{eV}$ Table 2. The interaction between PP and $\mathrm{CuO}$ through the $\mathrm{O}$ atom could be as element decoration at $\mathrm{H}$ number 31 , the $\mathrm{H}$ of the $\mathrm{CH}_{3}$ group. Finally, even when interacting with $\mathrm{Cu}$ atoms or $\mathrm{O}$ atoms, the electronic properties of $\mathrm{CuO}$ nano metal oxide influence the electronic properties of $\mathrm{PP}$ polymer. In the case of a CuOdecorated PP polymer, the $\mathrm{Cu}$ or $\mathrm{O}$ atom will interact with the $\mathrm{H}$ of the $\mathrm{CH}_{3}$ group and the $\mathrm{H}$ on the opposite side, allowing for sensing. In addition, the $\mathrm{CuO}$-decorated $\mathrm{PP}$ polymer with the $\mathrm{O}$ atom could be used as a component in sensor or optoelectronic devices [32-34]. 


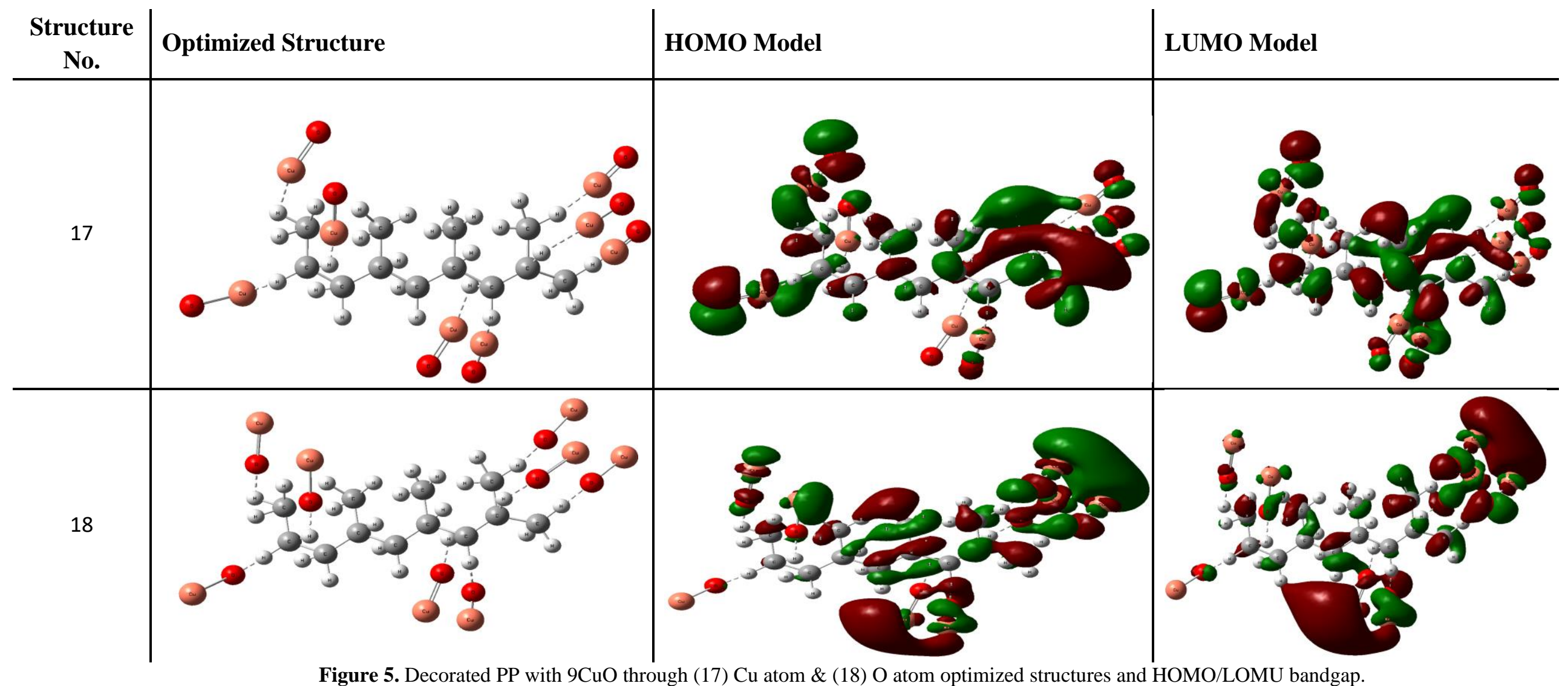

Table 2. Calculated total dipole moment (TDM) as Debye and HOMO/LUMO band gap energy $(\Delta \mathrm{E})$ as eV using DFT theory at B3LYP/6-311g(d,P) level for PP and decorated Polypropylene through $\mathrm{Cu}$ and $\mathrm{O}$ atom of $\mathrm{CuO}$.

\begin{tabular}{c|l|l|l} 
Structure No. & Structure & TDM & $\mathbf{\Delta} \mathbf{E}$ \\
\hline 17 & $\mathrm{PP}+9 \mathrm{CuO}$ & 13.30 & 0.37 \\
\hline 18 & $\mathrm{PP}+9 \mathrm{OCu}$ & 3.78 & 0.57
\end{tabular}


4. Conclusions

At the quantum mechanical DFT: B3LYP/6-311g(d,P) stage, the electronic properties of PP-CuO and PP-OCu composites are determined. The effect of $\mathrm{CuO}$ on TDM and $\triangle \mathrm{E}$ values in the results of calculations that are being performed for the model structures. Whereas the TDM of a PP molecule is 3.7 Debye, TDM values increased due to the addition of $\mathrm{CuO}$, reaching 20.34 Debye with the interaction that may occur at hydrogen atoms 17 and 14 in the first group. With the interaction, the value of $\Delta \mathrm{E}$ decreased from $1.2 \mathrm{eV}$ for the PP molecule to $0.3 \mathrm{eV}$. The addition of an OCu molecule increased the TDM of PP-OCu composites in the second group, but not as much as in the first group. Meanwhile, $\Delta \mathrm{E}$ values in the second group are lower than those in the first, dropping to $0.3 \mathrm{eV}$ Debye with the interaction, which may occur at the hydrogen atom number. The current computational model, which was used in these calculations, shows that the physical parameters studied are good indicators of the studied polymer/metal oxide system's reactivity. These results are in line with those of the previous study. It's possible that the composites studied could be used in sensors and other optoelectronic devices. The most probable interaction could be corresponding to the lowest value of $\Delta \mathrm{E}$. This was achieved for the interaction of PP with $\mathrm{OCu}$ in the second group at hydrogen atom number.

\section{Funding}

This research received no external funding.

\section{Acknowledgments}

This research has no acknowledgment.

\section{Conflicts of Interest}

The authors declare that they have no known competing financial interests or personal relationships that could have influenced the work reported in this paper.

\section{References}

1. Maddah, H.A. Polypropylene as a promising plastic: A review. J Am. J. Polym. Sci 2016, 6, 1-11, http://doi.org/10.5923/j.ajps.20160601.01.

2. He, C.; Costeux, S.; Wood-Adams, P.; Dealy, J.M. OMolecular structure of high melt strength polypropylene and its application to polymer design. $J$ Polymer 2003, 44, 7181-7188, http://doi.org/10.1016/j.polymer.2003.09.009.

3. De Santis, F.; Pantani, R. Optical properties of polypropylene upon recycling. J The Scientific World Journal 2013, 2013, https://doi.org/10.1155/2013/354093.

4. Gulrez, S.K.; Ali Mohsin, M.; Shaikh, H.; Anis, A.; Pulose, A.M.; Yadav, M.K.; Qua, E.H.P.; Al-Zahrani, S. A review on electrically conductive polypropylene and polyethylene. J Polymer composites 2014, 35, 900914, https://doi.org/10.1002/pc.22734.

5. Smith, A.L.; Capelli, E.; Konings, R.J.M.; Gheribi, A.E. A new approach for coupled modelling of the structural and thermo-physical properties of molten salts. Case of a polymeric liquid LiF-BeF2. J. Mol. Liq. 2020, 299, https://doi.org/10.1016/j.molliq.2019.112165

6. Galli, P.; Danesi, S.; Simonazzi, T. Polypropylene based polymer blends: fields of application and new trends. $J$ Polymer engineering science 1984, 24, 544-554. https://doi.org/10.1002/pen.760240807.

7. Shibata, M.; Xiaochuan, Z.; Yosomiya, R. Impact properties of the polymer blend of polypropylene and thermoplastic elastomer. Journal of Macromolecular Science -Pure Applied Chemistry 1998, 35, 1207-1215, https://doi.org/10.1080/10601329808002112. 
8. Ashori, A.; Nourbakhsh, A. Reinforced polypropylene composites: effects of chemical compositions and particle size. J Bioresource technology 2010, 101, 2515-2519, http://doi.org/10.1016/j.biortech.2009.11.022.

9. El-Sabbagh, A.M.M.; Steuernagel, L.; Meiners, D.; Ziegmann, G. Effect of extruder elements on fiber dimensions and mechanical properties of bast natural fiber polypropylene composites. Journal of Applied Polymer Science 2014, 131, https://doi.org/10.1002/app.40435.

10. Beaugrand, J.; Berzin, F. Lignocellulosic fiber reinforced composites: influence of compounding conditions on defibrization and mechanical properties. Journal of Applied Polymer Science 2013, 128, 1227-1238, https://doi.org/10.1002/app.38468.

11. Borysiak, S. Determination of nucleating ability ofwood for non-isothermal crystallisation of polypropylene. Journal of thermal analysis calorimetry 2007, 88, 455-462, http://doi.org/10.1007/s10973-006-8077-1.

12. Shubhra, Q.T.; Alam, A.; Quaiyyum, M. Mechanical properties of polypropylene composites: A review. Journal of thermoplastic composite materials 2013, 26, 362-391, https://doi.org/10.1177/0892705711428659.

13. Varga, J. $\beta$-modification of isotactic polypropylene: preparation, structure, processing, properties, and application. Journal of Macromolecular Science, Part B 2002, 41, 1121-1171, https://doi.org/10.1081/MB120013089.

14. Hassan, N.; Shahat, A.; El-Didamony, A.; El-Desouky, M.; El-Bindary, A. Synthesis and characterization of $\mathrm{ZnO}$ nanoparticles via zeolitic imidazolate framework-8 and its application for removal of dyes. Journal of molecular structure 2020, 1210, 128029, https://doi.org/10.1016/j.molstruc.2020.128029.

15. Meza-González, B.; Gómez-Espinosa, R.M.; Cortés-Guzmán, F. Computational modeling of metal ions removal by a modified polypropylene membrane. Chem.l Phys. Lett. 2020, 749, https://doi.org/10.1016/j.cplett.2020.137452.

16. Isseroff, L.Y.; Carter, E.A. Electronic structure of pure and doped cuprous oxide with copper vacancies: suppression of trap states. J Chemistry of Materials 2013, 25, 253-265, https://doi.org/10.1021/cm3040278.

17. Zhou, M.; Xiong, X.; Drummer, D.; Jiang, B. Interfacial interaction and joining property of direct injectionmolded polymer-metal hybrid structures: A molecular dynamics simulation study. Appl. Surf. Sci. 2019, 478, 680-689, https://doi.org/10.1016/j.apsusc.2019.01.286.

18. Wu, J.; Wang, X.; Li, H.; Wang, F.; Hu, Y. First-principles investigations on the contact electrification mechanism between metal and amorphous polymers for triboelectric nanogenerators. Nano Energy 2019, 63, https://doi.org/10.1016/j.nanoen.2019.103864.

19. Yao, Z.; Liu, S.; Zhang, L.; He, B.; Kumar, A.; Jiang, X.; Zhang, W.; Shao, G. Room temperature fabrication of p-channel $\mathrm{Cu} 2 \mathrm{O}$ thin-film transistors on flexible polyethylene terephthalate substrates. J Applied Physics Letters 2012, 101, 042114, https://doi.org/10.1063/1.4739524.

20. Hassan, N.; Shahat, A.; El-Didamony, A.; El-Desouky, M.; El-Bindary, A. Mesoporous iron oxide nano spheres for capturing organic dyes from water sources. J Journal of Molecular Structure 2020, 1217, 128361, https://doi.org/10.1016/j.molstruc.2020.128361.

21. Yu, J.; Liu, G.; Liu, A.; Meng, Y.; Shin, B.; Shan, F. Solution-processed p-type copper oxide thin-film transistors fabricated by using a one-step vacuum annealing technique. J Journal of Materials Chemistry C 2015, 3, 9509-9513, https://doi.org/10.1039/C5TC02384J.

22. Hassan, N.; Shahat, A.; El-Didamony, A.; El-Desouky, M.; El-Bindary, A. Equilibrium, Kinetic and Thermodynamic studies of adsorption of cationic dyes from aqueous solution using ZIF-8. J Moroccan Journal of Chemistry 2020, 8, 8-3, 2627-2637, https://doi.org/10.48317/IMIST.PRSM/morjchemv8i3.21127.

23. Mohammadi-Rad, N.; Esrafili, M.D.; Sardroodi, J.J. CuN3 doped graphene as an active electrocatalyst for oxygen reduction reaction in fuel cells: A DFT study. J. Mol. Graph. Model. 2020, 96, https://doi.org/10.1016/j.jmgm.2020.107537.

24. Malinenko, V.; Aleshina, L.; Pergament, A.; Germak, G. Switching Effects and Metal-Insulator Transition in Manganese Oxide. J Journal on Selected Topics in Nano Electronics Computing 2013, 1, 44-50, http://doi.org/10.15393/j8.art.2013.3005.

25. Benabid, F.; Kharchi, N.; Zouai, F.; Mourad, A.-H.I.; Benachour, D. Impact of co-mixing technique and surface modification of $\mathrm{ZnO}$ nanoparticles using stearic acid on their dispersion into HDPE to produce HDPE/ZnO nanocomposites. J Polymers Polymer Composites 2019, 27, 389-399, https://doi.org/10.1177/0967391119847353.

26. Arroyo, R.B. Structural characterization of the chromium-iron alloy formed by thermal diffusion processes. In Proceedings of Advanced Materials Research; 284-288. 
27. Ibrahim, M. Modeling the Effect of Zinc Oxide on the Electronic Properties of Polyvinyl Alcohol. J Egyptian Journal of Chemistry 2020, 63, 3-5, https://doi.org/10.21608/EJCHEM.2020.27245.2564.

28. El-Khodary, S.; Yahia, I.; Zahran, H.; Ibrahim, M. Preparation of polypyrrole-decorated MnO2/reduced graphene oxide in the presence of multi-walled carbon nanotubes composite for high performance asymmetric $\begin{array}{llllll}\text { supercapacitors. } \quad J \quad \text { Physica } \quad \text { B: } \quad \text { Condensed } & \text { Matter } & \text { 2019, } & \text { 556, }\end{array}$ https://doi.org/10.1016/j.physb.2018.11.070.

29. Zhang, Q.; Zhang, K.; Xu, D.; Yang, G.; Huang, H.; Nie, F.; Liu, C.; Yang, S. CuO nanostructures: synthesis, characterization, growth mechanisms, fundamental properties, and applications. J Progress in Materials Science 2014, 60, 208-337, https://doi.org/10.1016/j.pmatsci.2013.09.003.

30. Cho, S. Optical and electrical properties of $\mathrm{CuO}$ thin films deposited at several growth temperatures by reactive RF magnetron sputtering. $J$ Metals Materials International 2013, 19, 1327-1331, http://doi.org/10.1007/s12540-013-6030-y.

31. Maji, S.K.; Mukherjee, N.; Mondal, A.; Adhikary, B.; Karmakar, B. Chemical synthesis of mesoporous CuO from a single precursor: structural, optical and electrical properties. J Journal of Solid State Chemistry 2010, 183, 1900-1904, https://doi.org/10.1016/j.jssc.2010.06.007.

32. Mohamed, G.; Hassan, N.; Shahat, A.; El-Didamony, A.; Ashraf, A. Synthesis and Characterization of Porous Magnetite Nanosphere Iron Oxide as a Novel Adsorbent of Anionic Dyes Removal from Aqueous Solution. Biointerface Resarch in Applied Chemistry 2021, 11, 13377-13401, https://doi.org/10.33263/BRIAC115.1337713401.

33. Ezzat, H.A.; Hegazy, M.A.; Nada, N.A.; Osman, O.; Ibrahim, M.A.J.N.J.o.A. Application of natural polymers enhanced with $\mathrm{ZnO}$ and $\mathrm{CuO}$ as humidity sensor. J NRIAG Journal of Astronomy Geophysics 2020, 9, 586597, https://doi.org/10.1080/20909977.2020.1821573.

34. Bayoumy, A.M.; Ibrahim, M.; Omar, A. Mapping molecular electrostatic potential (MESP) for fulleropyrrolidine and its derivatives. $J$ Optical Quantum Electronics 2020, 52, 1-13, https://doi.org/10.1007/s11082-020-02467-6. 